\title{
Effect of calcitonin on anastrozole-induced bone pain during aromatase inhibitor therapy for breast cancer
}

\author{
P. Liu, D.Q. Yang, F. Xie, B. Zhou and M. Liu \\ Department of Surgery IV, Peking University People's Hospital, Beijing, China \\ Corresponding author: D.Q. Yang \\ E-mail:1pdqcn@126.com
}

Genet. Mol. Res. 13 (3): 5285-5291 (2014)

Received May 15, 2013

Accepted December 16, 2013

Published July 24, 2014

DOI http://dx.doi.org/10.4238/2014.July.24.7

\begin{abstract}
This study aimed to investigate calcitonin as an effective therapy for osteoporosis in patients with bone pain during the anastrozole treatment of breast cancer. Ninety-one patients, who were on anastrozole treatment for breast cancer and also suffered anastrozole-induced bone pain, were randomly divided into two groups: the calcitonin group received salmon calcitonin and Caltrate D, and the control group received Caltrate D. All patients were evaluated by the visual analogue scale (VAS) and underwent the dual energy x-ray absorptiometry test for bone mineral density (BMD), and serum osteocalcin (BGP), alkaline phosphatase (ALP), calcium (Ca), and phosphorus (P) were measured at three months before and after the treatment. Significant differences in serum Ca, $\mathrm{P}, \mathrm{BGP}$, and ALP were found in each group between before and after treatment $(\mathrm{P}<0.05)$, while no differences between the calcitonin and control groups were found. No difference was observed in femur BMD between the two groups, or between before and after treatment in each group. There was a significant difference in spine BMD between before and after treatment in the control group $(\mathrm{P}<0.05)$ but not in the calcitonin group, while no difference was found between the calcitonin and control groups. Futhermore, VAS score significantly declined in each
\end{abstract}


group after treatment $(\mathrm{P}<0.05)$, but much more in the calcitonin group than the control group $(\mathrm{P}<0.05)$. Our finding suggests that calcitonin may alleviate bone pain during the anastrozole treatment of breast cancer but has no effect on bone loss during cancer treatment.

Key words: Calcitonin; Bone pain; Anastrozole; Breast cancer; Aromatase inhibitor

\section{INTRODUCTION}

Adjuvant therapies are necessary and are of benefit for postoperative breast cancer patients (Cuzick et al., 2010; Jiang et al., 2010; Li et al., 2011). But the benefits of anastrozole in treating breast cancer have been accompanied by additional treatment-related toxicity. Therefore, patients with endocrine cancers have an increased risk of osteoporosis as a complication of cancer treatment (Hoff and Gagel, 2005; Body et al., 2007). Bone loss induced by hormone therapy appears in early breast cancer due to hypoestrogenism, and chemotherapy with resultant ovarian failure may also cause bone loss. Bone loss induced by cancer treatment can cause osteoporosis, decreased bone strength and increased risk of fracture (Cooper, 1997; Body et al., 2007). Bone loss induced by hormone therapy is usually rapid and severe, and associated with menopause in women. Thus, the risk of bone loss in breast cancer patients treated with aromatase inhibitor is at least twice that in healthy postmenopausal women (Hadji, 2009).

Calcitonin is a hormone produced in the thyroid glands. Hypocalcemic action for the inhibition of osteoclastic bone resorption leads to increased calcium and phosphorus in urinary excretion. Natural calcitonin and synthetic calcitonin have been clinically used. Salmon calcitonin is the most powerful and used to control bone pain due to malignant neoplasms (Parfitt, 1999). Salmon calcitonin can cause nausea, vomiting and flushing, unpleasant sensations in taste, tingling in hands, and pain at the site of injection. Some patients also experience an allergic reaction. In addition, salmon calcitonin is immunogenic and may develop antibodies, which can lead to drug resistance to its effects during long-term calcium treatment (GrahameSmith and Aronson, 2002; Lussier et al., 2004).

Currently, the use of calcitonin for relief of metastatic bone pain is not very common, and there is little information available about its use in anastrozole-induced bone pain during aromatase inhibitor therapy for breast cancer. However, there is strong evidence to support the use of risedronate in reducing the risk of both fractures, vertebral and nonvertebral, in postmenopausal women with osteoporosis and hypercalcemia (Zojer et al., 1999; Tugwell et al., 2003). The aim of this study was to investigate the effect of calcitonin as an effective therapy for osteoporosis in patients with bone pain during anastrozole treatment of breast cancer.

\section{MATERIAL AND METHODS}

\section{Patients}

Ninety-one breast cancer patients at Peking University People's Hospital, who were under anastrozole treatment for breast cancer and also suffered anastrozole-induced bone pain were enrolled. Full inclusion criteria were as follows: 1) age $\geq 60$ years old, or age $<60$ years 
old and with natural menopause of more than 1 year, or with bilateral oophorectomy; 2) undergoing adjuvant aromatase inhibitor therapy 2-4 weeks after surgery or 2-6 weeks after adjuvant chemotherapy; 3 ) estrogen receptor $\geq 10 \mathrm{fmol} / \mathrm{mg}$ or tumor cells $\geq 10 \%$ by histochemical detection. This study was conducted in accordance with the Declaration of Helsinki. And the study protocol was approved by the local research ethics committee of Peking University (Protocol Record D5395L00006). Written informed consent was obtained from all participants.

Patients were randomly allocated to one of two groups according to the drug received for three months: the calcitonin group received $200 \mathrm{IU} /$ day salmon calcitonin and $600 \mathrm{mg} /$ day Caltrate D, and the control group received $600 \mathrm{mg} /$ day Caltrate D.

\section{Visual analogue scale}

Pain level in patients was evaluated with a visual analog scale (VAS) of 0-10 three months before and after the treatment, where 0 was minimal and 10 was maximal pain.

\section{Dual energy x-ray absorptiometry}

Patients underwent the dual energy x-ray absorptiometry (DEXA) test for bone mineral density (BMD) three months before and after the treatment. BMD of spine and femur was determined by DEXA (DPXL/PED, Lunar Corp., Madison, WI, USA) according to the manufacturer standard spine and femur protocols.

\section{Biochemistry parameters measurements}

Serum osteocalcin (BGP), alkaline phosphatase (ALP), serum calcium (Ca) and phosphorus $(\mathrm{P})$ were also measured in patients three months before and after the treatment. BGP was measured by an EASIA kit (DRG Instruments GmbH, Marburg, Germany). A colorimetric assay kit (BioMerieux SA, France) was used to determine ALP activity as previously described (Belfield and Goldberg, 1971). Serum calcium and phosphorus were measured by atomic absorption spectroscopy.

\section{Statistical analysis}

The data are reported as means $\pm \mathrm{SD}$. Comparisons between groups of data were performed by the Wilcoxon test, while the Student $t$-test was used for within group comparisons. $\mathrm{P}<0.05$ was considered to be statistically significant. Data were analyzed with SAS9.2 (SAS Institute Inc., Cary, NC, USA).

\section{RESULTS}

\section{General data}

Nine patients were excluded from the study, three in the calcitonin group and six in the control group. Only 82 cases were analyzed. Basic characteristics of study population are shown in Table 1. 
Table 1. Basic characteristics of study population.

\begin{tabular}{|c|c|c|c|}
\hline & Control group $(\mathrm{N}=40)$ & Calcitonin group $(\mathrm{N}=42)$ & $P$ \\
\hline Age (years) & $61.3 \pm 6.9$ & $59.6 \pm 9.2$ & 0.357 \\
\hline Cancer stage & & & 0.8230 \\
\hline T1N0M0 & $17(42.50 \%)$ & $22(52.38 \%)$ & \\
\hline T1N0M1 & $0(0.00 \%)$ & $1(2.38 \%)$ & \\
\hline T1N1M0 & $8(20.00 \%)$ & $7(16.67 \%)$ & \\
\hline T1N2M0 & $1(2.50 \%)$ & $0(0.00 \%)$ & \\
\hline T2N0M0 & $10(25.00 \%)$ & $8(19.05 \%)$ & \\
\hline T2N1M0 & $4(10.00 \%)$ & $3(7.14 \%)$ & \\
\hline T3N0M0 & $0(0.00 \%)$ & $1(2.38 \%)$ & \\
\hline \multicolumn{4}{|l|}{ Chemotherapy } \\
\hline None & $24(60.00)$ & $26(61.90)$ & 0.860 \\
\hline Design & & & 0.129 \\
\hline $\mathrm{AC}$ & $9(22.50)$ & $3(7.14)$ & \\
\hline CAF & $3(7.50)$ & $4(9.52)$ & \\
\hline TA & $9(22.50)$ & $18(42.86)$ & \\
\hline TAC & $3(7.50)$ & $1(2.38)$ & \\
\hline Chronic illness & & & 0.6558 \\
\hline Hypertension & $3(7.50 \%)$ & $3(7.14 \%)$ & \\
\hline Cerebral infarction & $1(2.50 \%)$ & $0(0.00 \%)$ & \\
\hline Diabetes & $4(10.00 \%)$ & $2(4.76 \%)$ & \\
\hline None & $32(80.00 \%)$ & $37(88.10 \%)$ & \\
\hline Serum calcium & $2.29 \pm 0.10$ & $2.31 \pm 0.12$ & 0.402 \\
\hline Serum phosphorus & $1.26 \pm 0.18$ & $1.25 \pm 0.16$ & 0.817 \\
\hline Serum osteocalcin & $12.33 \pm 5.08$ & $15.26 \pm 9.98$ & 0.100 \\
\hline Alkaline phosphatase & $4.37 \pm 0.92$ & $4.95 \pm 2.58$ & 0.182 \\
\hline VAS & $4.48 \pm 1.48$ & $5.38 \pm 1.40$ & 0.006 \\
\hline BMD-spine & $-1.11 \pm 1.03$ & $-1.02 \pm 1.02$ & 0.717 \\
\hline BMD-femur & $-0.92 \pm 0.77$ & $-1.17 \pm 0.82$ & 0.160 \\
\hline Time of pain onset & $12.2 \pm 5.9$ & $10.9 \pm 4.4$ & 0.238 \\
\hline
\end{tabular}

$\mathrm{T} 1, \mathrm{~T} 2$ and $\mathrm{T} 3=$ tumor diameter $<2,2-5$ and $>5 \mathrm{~cm}$, respectively; N0, N1 and N2 = no axillary lymph node metastasis, axillary lymph node metastasis and axillary lymph node metastasis with fusion, respectively; M0 = no distant metastasis; $\mathrm{M} 1=$ distant metastasis; $\mathrm{AC}=$ adriamycin + cyclophosphamide; $\mathrm{CAF}=$ cyclophosphamide+adri amycin+fluorouracil; $\mathrm{TA}=$ taxinol+adriamycin; $\mathrm{TAC}=$ taxinol+adriamycin + cyclophosphamide.

\section{Changes in the biochemistry parameters}

As shown in Table 2, levels of serum Ca, P, BGP and ALP significantly decreased after aromatase inhibitor therapy in both calcitonin and control groups $(\mathrm{P}<0.05)$. However, no significant differences in levels of serum Ca, P, BGP, and ALP were observed after aromatase inhibitor therapy between the calcitonin and control groups.

Table 2. Comparison of biochemistry parameters between control and calcitonin group after therapy.

\begin{tabular}{|c|c|c|c|c|c|c|c|}
\hline & \multirow[t]{2}{*}{ Before therapy } & \multirow[t]{2}{*}{ After therapy } & \multirow[t]{2}{*}{ Difference value } & \multicolumn{2}{|c|}{ In group } & \multicolumn{2}{|c|}{ Between groups } \\
\hline & & & & Statistics & $\mathrm{P}$ & Statistics & $\mathrm{P}$ \\
\hline Serum calcium & & & & & & 0.0246 & 0.8758 \\
\hline Control & $2.29 \pm 0.10$ & $2.25 \pm 0.10$ & $-0.04 \pm 0.12$ & 2.2987 & 0.0270 & & \\
\hline Calcitonin & $2.31 \pm 0.12$ & $2.27 \pm 0.08$ & $-0.04 \pm 0.12$ & 2.0863 & 0.0432 & & \\
\hline Serum phosphorus & & & & & & 0.4323 & 0.5128 \\
\hline Control & $1.24(1.10-1.34)$ & $1.22(1.14-1.32)$ & $-1.06 \pm 0.14$ & 47.2093 & 0.0000 & & \\
\hline Calcitonin & $1.25(1.14-1.36)$ & $1.23(1.16-1.29)$ & $-1.08 \pm 0.17$ & 40.3782 & 0.0000 & & \\
\hline Serum osteocalcin & & & & & & 0.0974 & 0.9224 \\
\hline Control & $12.36(8.42-15.02)$ & $11.90(8.64-18.78)$ & $9.70(6.23-16.51)$ & 409.0000 & 0.0000 & & \\
\hline Calcitonin & $12.51(6.73-20.56)$ & $10.96(7.38-18.44)$ & $8.69(5.16-15.97)$ & 451.5000 & 0.0000 & & \\
\hline Alkaline phosphatase & & & & & & 0.4499 & 0.6528 \\
\hline Control & $4.37(3.78-5.13)$ & $4.33(3.46-5.11)$ & $2.04(1.12-2.92)$ & 409.0000 & 0.0000 & & \\
\hline Calcitonin & $4.57(3.45-5.75)$ & $4.40(3.23-5.12)$ & $2.02(1.06-2.75)$ & 444.5000 & 0.0000 & & \\
\hline
\end{tabular}




\section{Changes in BMD}

As shown in Table 3, spine BMD significantly decreased after therapy within the control group $(\mathrm{P}<0.01)$, but there was no change in the calcitonin group. A significant difference in spine BMD was observed after therapy between the control and calcitonin groups $(\mathrm{P}<$ 0.05). Furthermore, no statistical differences in femur BMD were found after therapy within or between the two groups.

Table 3. Comparison of bone mineral density (BMD) between control and calcitonin group.

\begin{tabular}{|c|c|c|c|c|c|c|c|}
\hline & \multirow[t]{2}{*}{ Before therapy } & \multirow[t]{2}{*}{ After therapy } & \multirow[t]{2}{*}{ Difference value } & \multicolumn{2}{|c|}{ In group } & \multicolumn{2}{|c|}{ Between groups } \\
\hline & & & & Statistics & $P$ & Statistics & $P$ \\
\hline BMD-spine & & & & & & 2.0562 & 0.0398 \\
\hline Control & $-1.15(-1.95-0.45)$ & $-1.25(-2.20-0.80)$ & $-0.10(-0.35-0.10)$ & 156.0000 & 0.0057 & & \\
\hline Calcitonin & $-1.10(-1.90-0.30)$ & $-1.30(-1.80-0.20)$ & $0.00(-0.20-0.20)$ & 15.0000 & 0.8019 & & \\
\hline BMD-femur & & & & & & 0.0020 & 0.9641 \\
\hline Control & $-0.92 \pm 0.77$ & $-0.91 \pm 0.75$ & $0.01 \pm 0.47$ & 0.0672 & 0.9468 & & \\
\hline Calcitonin & $-1.17 \pm 0.82$ & $-1.17 \pm 0.90$ & $-0.00 \pm 0.53$ & 0.0000 & 1.0000 & & \\
\hline
\end{tabular}

\section{Changes in VAS}

As shown in Table 4, the VAS score was significantly decreased after therapy within both the control and calcitonin groups $(\mathrm{P}<0.01)$. A significant difference in VAS was also observed after therapy between the control and calcitonin groups $(\mathrm{P}<0.01)$.

Table 4. Comparison of visual analogue scale (VAS) between control and calcitonin group.

\begin{tabular}{|c|c|c|c|c|c|c|c|}
\hline & \multirow[t]{2}{*}{ Before therapy } & \multirow[t]{2}{*}{ After therapy } & \multirow[t]{2}{*}{ Difference value } & \multicolumn{2}{|c|}{ In group } & \multicolumn{2}{|c|}{ Between groups } \\
\hline & & & & Statistics & $P$ & Statistics & $P$ \\
\hline VAS & & & & & & 5.6286 & 0.0000 \\
\hline Control & $4.00(3.50-5.00)$ & $4.00(1.00-8.00)$ & $-1.00(-1.50-0.00)$ & 129.0000 & 0.0013 & & \\
\hline Calcitonin & $5.00(5.00-6.00)$ & $2.00(0.00-7.00)$ & $-3.00(-4.00--2.00)$ & 440.5000 & 0.0000 & & \\
\hline
\end{tabular}

\section{DISCUSSION}

This study included the trial involving a total of 91 patients who were treated for anastrozole-induced bone pain with a dose of $200 \mathrm{IU}$ calcitonin per day or placebo. Due to its effects by inhibiting the absorption of osteoclasts and its analgesic activity, it has been hypothesized that calcitonin could be beneficial in treating bone pain, but there is no evidence for the treatment of bone loss.

Calcitonin is found in several species, but that from the salmon is the most widely used because of the characteristics that make it highly potent, namely long half-life, resistance to degradation in plasma and high affinity to specific receptors (Berne and Levy, 1990; Reginster, 1991; Siligardi et al., 1994).

The bone repair is activated by growth hormones and thyroid and parathyroid hormones, and inhibited by calcitonin and cortisone. A temporary interruption of blood with the combination of devitalized bone and tissue necrosis causes the activation of bone repair (Hollinger and Wong, 1996). It is believed that this regeneration occurs based on two combined 
mechanisms: induction of proliferation and differentiation of undifferentiated mesenchymal cells, and the induction of osteoprogenitor cell proliferation. One of the most common consequences of hormone loss is osteoporosis due to estrogen deficiency and pathology. Osteoporosis is currently defined as a systemic skeletal disease characterized by low bone mass with impaired tissue microstructure. Osteoporosis is the consequence of a breakdown in bone metabolism characterized by a progressive pathological bone resorption, accompanied by a reduced osteogenesis. This low bone mass is attributed to estrogen deficiency, and decreased bone density with age can be explained at least partly by increased secretion of parathyroid hormone resulting from vitamin D deficiency and low calcium absorption (Young et al., 1987).

Calcitonin is a hypocalcemic thyroid hormone, secreted in the parafollicular cells of the thyroid gland of mammals and actively participates in skeletal homeostasis, as it normalizes the concentration of calcium ions in the plasma. It is a single chain peptide, and its biosynthesis and secretion is regulated by calcium concentration in plasma (Copp et al., 1962). Hypocalcemic and hypophosphatemic effects of calcitonin are caused predominantly by direct inhibition of osteoclastic bone resorption and influence on renal function (Reginster et al., 1992). However, no statistical improvement of BMD in patients was found with calcitonin treatment during anastrozole treatment of breast cancer (Table 3).

Pain relief should be the first target in the treatment of bone pain during anastrozole treatment of breast cancer to improve patients' quality of life. There are different levels of treatment for the relief of pain, which usually begin with an analgesic or nonsteroidal anti-inflammatory drug, and continues with low potency opioids (codeine), and then with other more potent opioids (morphine). However, this drug sequence fails for a variety of reasons, because the medications are not prescribed at higher therapeutic doses. Radiation therapy is commonly used to provide relief from localized painful bone metastases (Hoskin, 1995). About 75\% of patients achieve pain relief, and half of them remain free of pain (Jacox et al., 1994). However, in the event of multiple bone metastases, systemic treatments such as bisphosphonates or calcitonin may be necessary for efficacy. Our finding showed that VAS score significantly decreased after therapy in the calcitonin group compared with control group $(\mathrm{P}<0.01)$, shown in Table 4. Similar results have been obtained showing efficacy in trials of calcitonin with cancer bone pain management in patients (Wong and Wiffen, 2002).

In summary, our findings suggest that calcitonin can alleviate bone pain during anastrozole treatment of breast cancer but has no effect on bone loss during cancer treatment.

\title{
ACKNOWLEDGMENTS
}

\author{
Research supported by Astrazeneca.
}

\section{REFERENCES}

Belfield A and Goldberg DM (1971). Revised assay for serum phenyl phosphatase activity using 4-amino-antipyrine. Enzyme 12: 561-573.

Berne RM and Levy MN (1990). Fisiologia. 2nd edn. Guanabara, Rio de Janeiro.

Body JJ, Bergmann P, Boonen S, Boutsen Y, et al. (2007). Management of cancer treatment-induced bone loss in early breast and prostate cancer - a consensus paper of the Belgian Bone Club. Osteoporos. Int. 18: 1439-1450.

Cooper C (1997). The crippling consequences of fractures and their impact on quality of life. Am. J. Med. 103: 12S-17S.

Copp DH, Cameron EC, Cheney BA, Davidson AG, et al. (1962). Evidence for calcitonin-a new hormone from the parathyroid that lowers blood calcium. Endocrinology 70: 638-649. 
Cuzick J, Sestak I, Baum M, Buzdar A, et al. (2010). Effect of anastrozole and tamoxifen as adjuvant treatment for earlystage breast cancer: 10-year analysis of the ATAC trial. Lancet Oncol. 11: 1135-1141.

Grahame-Smith DG and Aronson JK (2002). The Drug History and the Clinical Examination and Investigation of Drug Effects. In: The Oxford Textbook of Clinical Pharmacology and Drug Therapy. 3rd edn (Graheme-Smith DG and Aronson JK, eds.). Oxford University Press, Oxford, 167-170.

Hadji P (2009). Aromatase inhibitor-associated bone loss in breast cancer patients is distinct from postmenopausal osteoporosis. Crit. Rev. Oncol. Hematol. 69: 73-82.

Hoff AO and Gagel RF (2005). Osteoporosis in breast and prostate cancer survivors. Oncology 19: 651-658.

Hollinger J and Wong ME (1996). The integrated processes of hard tissue regeneration with special emphasis on fracture healing. Oral Surg. Oral Med. Oral Pathol. Oral Radiol. Endod. 82: 594-606.

Hoskin PJ (1995). Radiotherapy for bone pain. Pain 63: 137-139.

Jacox A, Carr DB, Payne R, Berde CB, et al. (1994). Management of Cancer Pain. Clinical Practice Guideline No 9. Agency for Health Care Policy and Research, US Department of Health and Human Services, Rockville, 41-74.

Jiang Y, Huang XE, Yan PW, Cui L, et al. (2010). Validation of treatment efficacy of a computer-assisted program for breast cancer patients receiving postoperative adjuvant chemotherapy. Asian Pac. J. Cancer Prev. 11: 1059-1062.

Li Y, Tang JH, Huang XE and Li CG (2011). Clinical comparison on the safety and efficacy of fluorouracil/pirarubicin/ cyclophosphamide (FPC) with fluorouracil/epirubicin/cyclophosphamide (FEC) as postoperative adjuvant chemotherapy in breast cancer. Asian Pac. J. Cancer Prev. 12: 1795-1798.

Lussier D, Huskey AG and Portenoy RK (2004). Adjuvant analgesics in cancer pain management. Oncologist 9: 571-591. Parfitt K (1999). Martindale: the complete drug reference. 32nd edn. Pharmaceutical Press, London, 1257-1258.

Reginster JY, Azria M, Gaspar S, Bleicher M, et al. (1992). Endogenous production of specific antibodies does not decrease hypocalcemic response to calcitonin in young rabbits. Calcif. Tissue Int. 50: 518-520.

Reginster JY (1991). Effect of calcitonin on bone mass and fracture rates. Am. J. Med. 91: 19-22.

Siligardi G, Samori B, Melandri S, Visconti M, et al. (1994). Correlations between biological activities and conformational properties for human, salmon, eel, porcine calcitonins and Elcatonin elucidated by CD spectroscopy. Eur. J. Biochem. 221: 1117-1125.

Tugwell P, Wells G, Shea B and Peterson J (2003). Hormone Replacement Therapy for Osteoporosis in Postmenopausal Women (Protocol for a Cochrane Review). The Cochrane Library, Oxford: Update Software, 3.

Wong R and Wiffen PJ (2002). Bisphosphonates for the relief of pain secondary to bone metastases. Cochrane Database Syst. Rev. CD002068.

Young G, Marcus R, Minkoff JR, Kim LY, et al. (1987). Age-related rise in parathyroid hormone in man: the use of intact and midmolecule antisera to distinguish hormone secretion from retention. J. Bone Miner. Res. 2: 367-374.

Zojer N, Keck AV and Pecherstorfer M (1999). Comparative tolerability of drug therapies for hypercalcaemia of malignancy. Drug Saf. 21: 389-406. 